\title{
Constitutive and Inducible Secretion of Platelet-derived Growth Factor Analogs by Human Leukemic Cell Lines Coexpressing Erythroid and Megakaryocytic Markers
}

\author{
Th. Papayannopoulou, ${ }^{*}$ E. Raines, ${ }^{*}$ S. Collins, 5 B. Nakamoto, ${ }^{*}$ M. Tweeddale," and R. Ross ${ }^{\ddagger}$ \\ ${ }^{*}$ Division of Hematology, Department of Medicine, and ${ }^{\ddagger}$ Department of Pathology, University of Washington, Seattle, Washington 98195 ; \\ ${ }^{\S}$ Fred Hutchinson Cancer Research Center, Seattle, Washington 98104; \\ "Ontario Cancer Institute, Toronto, Canada M4X $1 \mathrm{~K} 9$
}

\begin{abstract}
We have examined the constitutive and inducible secretion of platelet-derived growth factor (PDGF)-like proteins in a variety of human hemopoietic cell lines. The highest levels of secreted protein were noted in four human erythroleukemia lines which, in addition to erythroid lineage markers, express one or more megakaryocytic lineage markers. Induction of these lines by 12$O$-tetradecanoylphorbol-13-acetate enhanced the expression of megakaryocytic markers and increased secretion of PDGF-like proteins several fold. In concert with these changes, there was significant induction of c-sis/PDGF-B messenger RNA (mRNA) expression in all lines, whereas one line showed significant concurrent induction of PDGF-A mRNA expression. Whether PDGF-like secretion is part of the stem cell-like phenotype displayed by these lines or is secondary to their leukemic transformation remains to be determined. Nevertheless, these lines provide new cellular models for studying the expression and function of PDGF analogs in hemopoietic cells.
\end{abstract}

\section{Introduction}

Platelet-derived growth factor (PDGF) ${ }^{1}$ is a potent mitogen for many connective tissue cells in culture (1-4). PDGF exerts its function by binding to specific cell surface receptors on responsive cells (5) and thereby triggering a number of intracellular events culminating in cell division (6). A major source of PDGF is the $\alpha$-granules of platelets. PDGF released from activated platelets in vivo could play a role in normal wound repair (1, $2,4)$ and in the development of lesions of atherosclerosis $(4,7)$. In addition to platelet-stored PDGF, which appears to be synthesized earlier in megakaryocytes $(8,9)$, several other cellular sources of PDGF-like molecules have been identified. These include cultured endothelial cells $(10,11)$, activated macrophages (12-14), newborn rat aortic smooth muscle cells (15), and human cytotrophoblasts (16), all of which secrete PDGF-like molecules in culture. Furthermore, cells transformed by a wide variety of transforming agents that do not themselves encode for a PDGFlike molecule, secrete a PDGF-like molecule into their media

Received for publication 4 August 1986.

1. Abbreviations used in this paper: FITC, fluorescein isothiocyanate; GP, glycoprotein; HEL, human erythroleukemia; PDS, plasma-derived serum; PDGF, platelet-derived growth factor; PMA, phorbol 12-myristate 13-acetate; TPA, 12-O-tetradecanoylphorbol 13-acetate; vWF, von Willebrand factor.

J. Clin. Invest.

(c) The American Society for Clinical Investigation, Inc.

0021-9738/87/03/0859/08 \$1.00

Volume 79, March 1987, 859-866
(17-19). Thus, it has been speculated that PDGF may contribute not only to the process of transformation and uncontrolled proliferation of some malignant cells, but, in addition, to processes of normal proliferation and differentiation.

Because synthesis of PDGF is associated with cells of megakaryocytic lineage, we examined in the present study whether hemopoietic cell lines previously found to express one or more megakaryocytic markers (20-23) are capable of synthesizing or secreting PDGF. Parallel observations with other nonlymphoid hematopoietic cell lines not expressing these markers were also carried out. Inasmuch as an enhancement of megakaryocytic marker expression has been observed after addition of certain compounds (23), we also determined whether the same agents could augment production or release of PDGF.

Our results show that several hemopoietic cell lines produce PDGF analogs by protein and messenger RNA (mRNA) measurements, especially after induction. They also establish an association between PDGF secretion and megakaryocytic marker expression and a coordinate enhancement of both of these features by addition of phorbol diesters. Whether PDGF is part of the cells' megakaryocytic differentiation program, or whether it is a manifestation of their hemopoietic immaturity and/or their transformed nature is unclear and requires further study. Our data, nevertheless, provide new information about in vitro activation of PDGF-A and PDGF-B sequences (coding for A or $B$ chain of PDGF) and secretion of PDGF-like molecules in hematopoietic cell lines.

\section{Methods}

Hematopoietic cell lines. We selected 11 permanent human leukemic cell lines for evaluation. These represent a spectrum of nonlymphoid hematopoietic cell lines in various stages of differentiation (Table I). Five of the lines (K562, K562[S], HEL, OCIM1, OCIM2) have been assigned as erythroleukemic, in that they display erythroid markers and synthesize hemoglobin (24-27). Five lines (KG1, KG-1a, HL-60, EM2, EM3) express myeloid features (28-31) and one (U-937) is of monoblastic-histiocytic origin (32).

Fibroblasts, endothelial cells and $3 T 3$ cells. Normal human adult foreskin fibroblasts were obtained from explants and juvenile human skin fibroblasts from the American Type Culture Collection (Rockville, MD). Swiss 3T3D1 cells are a clone selected from Swiss 3T3 cells obtained from R. Pollack (Columbia University). The Swiss 3T3 D1 clone was selected in our laboratory for its quiescence in plasma-derived serum (PDS) and its responsiveness to added PDGF.

Cell cultures and differentiation induction. All hematopoietic cell lines, except two, were maintained in RPMI 1640 (Whitakker, M.A. Bioproducts, Walkersville, MD) supplemented with $10 \%$ fetal calf serum (FCS), glutamine, and antibiotics. The cell cultures were split and fed with fresh media twice a week. The OCIM1 and OCIM2 cells were maintained in tissue culture flasks using Iscove's modified Dulbecco's medium (IMDM, Gibco, Grand Island, NY) with 10\% FCS (Armour Pharmaceutical Co., Tarrytown, NY) and $5 \times 10^{-5} \mathrm{M}$ 2-mercaptoethanol. Two 
Table I. Human Hematopoietic Cell Lines Examined

\begin{tabular}{lll}
\hline Line & Predominant phenotype & Reference \\
\hline K-562(C-16) & Erythroleukemic & 24 \\
K-562(S) & Erythroleukemic & 25 \\
HEL & Erythroleukemic & 26 \\
OCIM1 & Erythroleukemic & 27 \\
OCIM2 & Erythroleukemic & 27 \\
KG1 & Myeloid & 28 \\
KG1A & Undifferentiated & 29 \\
EM2 & Undifferentiated & 31 \\
EM3 & Undifferentiated & 31 \\
HL-60 & Promyelocytic & 30 \\
U-937 & Monoblastic & 32 \\
& & \\
\hline
\end{tabular}

agents were used for induction: phorbol 12-myristate 13-acetate (PMA) or 12-O-tetradecanoylphorbol 13-acetate (TPA) (L.C. Services Corp., Woburn, MA) and dimethyl sulfoxide (DMSO, J. T. Baker Chemical Co., Phillipsburg, NJ). $2 \mathrm{~d}$ before induction, the cells were transferred to the same medium, but with $1 \%$ human PDS, which was prescreened and contained undetectable levels of PDGF. After this preconditioning with PDS, the cells were centrifuged, diluted with fresh medium $+1 \%$ PDS to a concentration of $1 \times 10^{6} \mathrm{cells} / \mathrm{ml}$ and transferred to fresh flasks. TPA was added at a concentration of $1.6 \times 10^{-7} \mathrm{M}$, and an equal number of cells were incubated without TPA. DMSO was used as $1 \%$ solution in media + PDS. After a 48-h incubation in the presence of the inducer, the mixture of cells and medium were separated by centrifugation, the pelleted cells were pooled and counted, and both the cells and the supernatant medium were processed for determination of PDGF levels by radioreceptor assay. If the cells became adherent during the 2-d incubation, cold phosphate-buffered saline (PBS) was added to the flasks, and they were refrigerated for 1-2 $\mathrm{h}$ with gentle shaking and sometimes scraped with a sterile cell scraper to recover all the cells. The cells were counted in a hemocytometer and the total number of cells as well as viable cells were estimated by trypan blue dye exclusion. Cell lysates were prepared by repeated freezing and thawing in PBS. In selected experiments, media from TPA-treated OCIM2 cells were collected in the presence and absence of actinomycin $\mathrm{D}(2.5 \mu \mathrm{g} / \mathrm{ml})$ or cycloheximide $(5 \mu \mathrm{g} / \mathrm{ml})$. The media were concentrated $\sim 10$-fold using Amicon ultrafiltration and a YM-10 membrane (Amicon Corp, Danvers, MA).

Assay for PDGF receptor competitive activity. Subconfluent cultures of human adult foreskin fibroblasts or juvenile human skin fibroblasts (American Type Culture Collection) were prepared in 2-cm ${ }^{2}$ 24-well culture dishes (Costar, Cambridge, MA) in 1\% human PDS and used for determination of PDGF levels in test samples using the radioreceptor assay described previously (33). Briefly, the cultures were rinsed once with binding rinse (ice-cold PBS containing $1 \mathrm{mg} / \mathrm{ml}$ bovine serum albumin [BSA]) and then incubated on an oscillating table with 0.5 or 1 $\mathrm{ml}$ per well of binding media containing the test sample or standard concentrations of PDGF. After $3 \mathrm{~h}$, the test samples were aspirated, and the wells rinsed once with binding rinse, and incubated for one additional hour at $4^{\circ} \mathrm{C}$ with binding medium containing $0.5 \mathrm{ng} / \mathrm{ml}{ }^{125} \mathrm{I}$-PDGF. Binding was terminated by washing three times with binding rinse, and cell-associated ${ }^{125}$ I-PDGF was extracted with $1 \%$ Triton X-100 in $0.1 \%$ BSA. Highly purified PDGF was prepared as described (34) and was radioiodinated to a specific activity of $20,000-40,000 \mathrm{cpm} / \mathrm{ng}(33)$.

RNA extraction, Northern and dot blot hybridization. Cells were homogenized in guanidine thiocyanate (Eastman Kodak Co., Rochester, NY) and subjected to ultracentrifugation through a cesium chloride cushion as described by Chirgwin et al. (35). The RNA pellet was suspended in $0.3 \mathrm{ml}$ of water. Total RNA was enriched for polyadenylatecontaining RNA by one cycle of oligo dT cellulose affinity chromatography (36). RNA concentration was estimated by OD 260 determination. For Northern blot analysis, portions $(5 \mu \mathrm{g})$ of polyadenylated RNA were subjected to electrophoresis in formaldehyde gels and transferred to nitrocellulose filters as described (37). The filter was baked for $2 \mathrm{~h}$ at $80^{\circ} \mathrm{C}$ and then hybridized to a gel-purified and nick-translated 1.7-kb Bam csis fragment representing the $3^{\prime}$ exon of human proto-oncogene c-sis $(38,39)$ or to the PDGF-A chain cDNA probe (clone D1, $1.3 \mathrm{~kb})(40)$. Hybridizations were performed in $50 \%$ formamide/ $10 \%$ dextran sulfate/ $0.45 \mathrm{M} \mathrm{NaCl} / 0.045 \mathrm{M}$ trisodium citrate for $36 \mathrm{~h}$ at $42^{\circ} \mathrm{C}$. After hybridization filters were washed in $0.1 \% \mathrm{SDS} / 5 \mathrm{mM} \mathrm{NaCl} / 1.5 \mathrm{mM}$ trisodium citrate at $50^{\circ} \mathrm{C}$, dried, and exposed to Kodak XAR- 5 film. Sizes of transcripts in kilobases were determined by comparison with $28 \mathrm{~S}(5.0 \mathrm{~kb})$ and $18 \mathrm{~S}(2.0 \mathrm{~kb})$ ribosomal RNA bands visualized by ethidium bromide staining of a marker lane excised from each gel before nitrocellulose transfer. For dot blots polyadenylated RNA was diluted in $100 \mu \mathrm{l}$ of water containing $6 \times$ standard saline citrate (SSC) and $2.2 \mathrm{M}$ formaldehyde and then heated for $15 \mathrm{~min}$ at $60^{\circ} \mathrm{C}$. The samples were chilled on ice and then applied with HybriDot manifold (Bethesda Research Laboratories, Gaithersburg, MD) to a nitrocellulose filter previously soaked in $20 \times$ SSC. The filter was dried under a heat lamp, baked, hybridized, and washed exactly as described above.

Immunofluorescence studies. Immunofluorescence studies were carried out in cell lines before and after the addition of TPA or DMSO. Treated cells were harvested $48 \mathrm{~h}$ after treatment, washed in PBS $+1 \%$ BSA $+0.01 \%$ sodium azide, and subjected to specific antibody labeling as follows. To a small aliquot of cells a few $\lambda(10-50)$ of an appropriately diluted monoclonal antibody (either semipurified or as ascites fluid) was added. After a 30-min incubation at room temperature, the cells were washed three times with PBS, then a small amount of appropriately diluted fluorescein isothiocyanate (FITC)-labeled $F\left(a^{\prime}\right)_{2}$ anti-mouse IgG was added and incubated for $1 \mathrm{~h}$. After washing, the preparations were subjected to fluorographic analysis in a fluorescence-activated cell sorter (Ortho Cytoflurograf-50H, Westwood, MA). Control untreated cells were labeled similarly. Three antibodies reacting with glycoprotein (GP) IIb/ IIIa complex were used: a polyclonal antibody, kindly donated by $\mathrm{Dr}$. R. Hoffman and two monoclonal antibodies (AP-2 and 13.1) kindly supplied by Dr. D. Nugent (41). One antibody against GP IIb (G1.9.I.3) and one against GP IIIa (B79.7) were generously supplied by Dr. Thiagarajan (42). Two monoclonal antibodies against GP Ib, (6D1 and C7E10) were supplied by Drs. J. Roth and D. Nugent (43). Methanol fixed cytocentrifuge preparations of cells from the different cell lines were also labeled with a monoclonal anti-von Willebrand factor antibody (CLBRAg20, provided by Dr. Jan A. van Mourik, Central Laboratory of the Netherlands Red Cross Blood Transfusion Service, Amsterdam) in an indirect assay. Preparations were viewed in a Zeiss Universal epifluorescence microscope (Carl Zeiss, Inc., Thornwood, NY) under the appropriate filters.

\section{Results}

Production of PDGF-like molecules by 11 hematopoietic cell lines before and after induction with TPA. Media and cell extracts of the nonlymphoid hematopoietic cell lines listed in Table I were evaluated for production of functional PDGF-like molecules by PDGF radioreceptor assay (33). All cell lines were free of mycoplasma and were preconditioned in 1\% human PDS known to be free of detectable levels of PDGF. PDGF levels were determined on media from cells maintained for $48 \mathrm{~h}$ in the presence or absence of $1.6 \times 10^{-7} \mathrm{M}$ TPA. The data are illustrated in Fig. 1 and have been normalized to final cell number at the end of 48 hours. Without the addition of TPA, five cell lines contained undetectable levels of PDGF $\left(<0.007 \mathrm{ng} / 10^{6}\right.$ cells $)$ and the remainder had levels varying from 0.03 to $0.4 \mathrm{ng} / 10^{6}$ cells (Fig. 1). Treatment of the cell lines with $1.6 \times 10^{-7} \mathrm{M}$ TPA during the 48-h collection period resulted in up to a 10 -fold induction of PDGF-like molecule secretion. The results from induced cells are plotted in decreasing order in Fig. 1 according to the levels of PDGF, with the higher levels on the left. The five cell lines, 


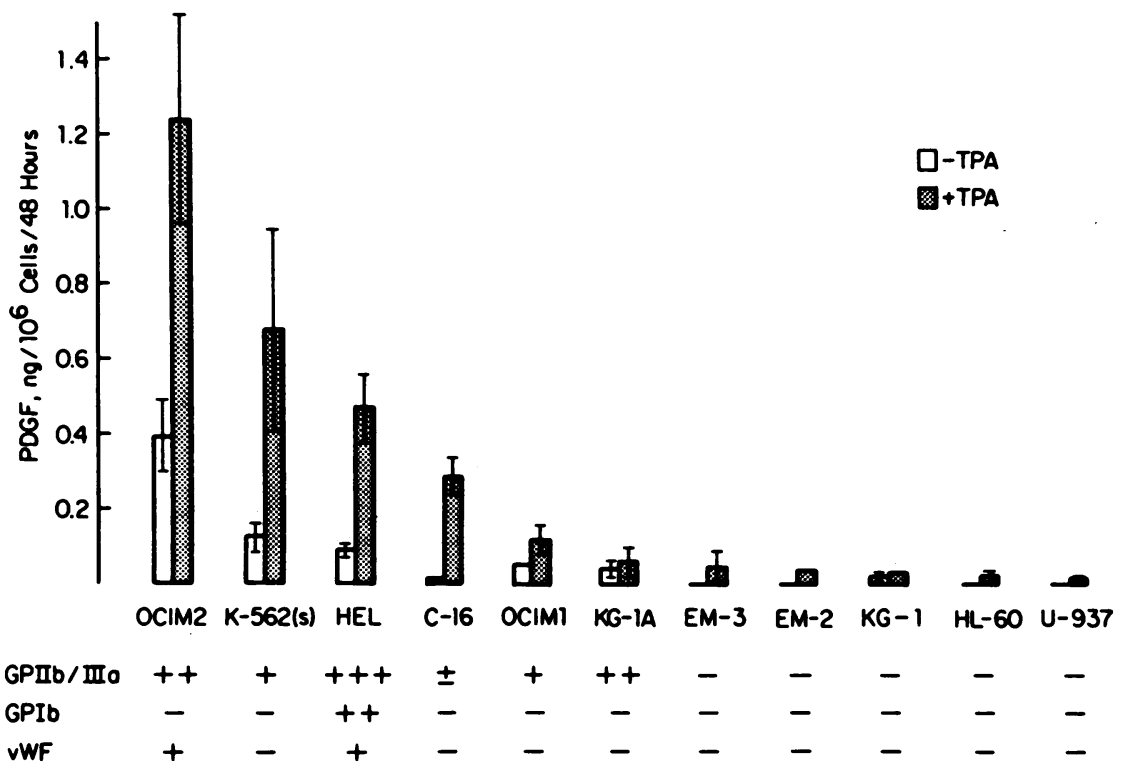

Figure 1. Secretion of PDGF-like molecules by 11 human nonlymphoid hematopoietic cell lines and expression of platelet/megakaryocytic cell markers. Media conditioned by the 11 human cell lines listed in Table $\mathrm{I}$, in the presence or absence of TPA, were collected after $48 \mathrm{~h}$ and the levels of PDGF were determined by a PDGF radioreceptor assay as described in Methods. The average of duplicate collections and the range of these determinations are plotted and normalized to the final cell number at $48 \mathrm{~h}$ except OCIM2, K562(S), and HEL which represent a mean and standard error of three, three, and five collections, respectively, and EM-2 which is a single collection. A number of platelet/megakaryocytic markers were also evaluated by immunofluorescence and the degree of positivity is denoted by the number of + signs. These markers include platelet glycoproteins IIb/IIIa, GPIIb/IIIa; platelet glycoprotein Ib, GPIb; and von Willebrand factor, vWF.

(OCIM2, K562(S), HEL, K562(C-16), OCIM1), producing the most significant levels of PDGF were all cells of erythroleukemic origin. The remaining six cell lines had much lower or undetectable levels of PDGF either before or after TPA addition and none were of erythroleukemic affiliation. The possibility, however, that some PDGF is present in the media from some of these lines, but in association with a binding protein, and therefore not detectable, as described for macrophages (12), cannot be excluded. Induction of PDGF-like secretion was not observed in OCIM2 after addition of the inactive phorbol, $4 \beta$-phorbol, or after addition of $\alpha$-thrombin (Table II).

Lysates of the cells used for collection of the conditioned media were also evaluated for levels of PDGF-like molecules. Without induction, no soluble intracellular PDGF was detectable $\left(<0.005 \mathrm{ng} / 10^{6}\right.$ cells; membrane associated PDGF was not tested). After induction, intracellular PDGF was detectable only in OCIM2, $\mathrm{K} 562(\mathrm{~S})$, and $\mathrm{K} 562(\mathrm{C}-16)$. These levels represented less than $4 \%, 13 \%$, and $9 \%$, respectively, of the amount of PDGF accumulated in the media over a 6-h collection period. Screening of the same cell lysates by a quantitative enzyme-linked immunosorbent assay (ELISA) for PDGF did not demonstrate higher levels of intracellular PDGF (data not shown). Therefore, no evidence was obtained for the presence of an inactive, stored precursor in any of the cell lines tested.

Table II. TPA Induction of OCIM2 Secretion of PDGF-like Molecules Is Specific and Is Sensitive to Actinomycin and Cycloheximide

\begin{tabular}{llc}
\hline Inducer & Treatment & PDGF \\
\hline & & $n g / 10^{6}$ cells \\
None & None & $0.19 \pm 0.019$ \\
TPA & None & $1.24 \pm 0.4$ \\
$4 \beta$-Phorbol & None & $0.14 \pm 0.014$ \\
$\alpha$-Thrombin & None & $0.21 \pm 0.028$ \\
TPA & Actinomycin-D & $0.083 \pm 0.020$ \\
TPA & Cycloheximide & $0.19 \pm 0.004$ \\
& & \\
\hline
\end{tabular}

Coordinate expression of platelet-megakaryocytic markers and PDGF-like secretion. All the cell lines included in our survey were tested for the presence of surface membrane glycoproteins characteristic for cells of platelet-megakaryocytic origin (Fig. 1). Polyclonal and monoclonal antibodies against the complex GP IIb/IIIa (Fig. 2) and GP Ib (Fig. 3), as well as monoclonal antibodies reacting specifically with either GP IIb or GPIIIa (Fig. 3 ), were employed in indirect immunofluorescence assays. In accord with previous studies on human erythroleukemia (HEL) and K562 cells $(22,23)$, high reactivity against GP IIb/IIIa was observed with all HEL-derived sublines, whereas relatively less reactivity was present in the $\mathrm{K} 562$ sublines, (K562(S) and K562(C-16)) (Fig. 2 and data not shown). In addition, the present studies uncovered reactivities against the GP IIb/IIIa complex, using both polyclonal and monoclonal antibodies in two additional lines: OCIM2 and KG-1a, whereas the remainder were negative. GP Ib was detected only in HEL cells (Fig. 3), whereas the presence of intracellular vWF antigen was noted in some cells from both the HEL cell line and the OCIM2 and in none of the remaining cell lines (Table I). In general, the expression of platelet glycoproteins (specifically GP IIb/IIIa or GP IIIa) was enhanced after treatment of cells with either TPA or DMSO, and the augmentation of reactivity was more pronounced when FCS-maintained cells were treated as opposed to cells treated in the presence of PDS (data not shown). The appearance of few positive cells with anti-GP IIb/IIIa was also noted in U-937 cells after TPA treatment (when polyclonal anti-GP IIb/IIIa was used, more positive cells were seen). The most significant increase in the expression of GP IIb/IIIa compared with pretreatment levels was observed in $\mathrm{K} 562$ (S) cells (Fig. 2). This increase concerned solely GP IIIa, as independent labeling with only anti-GP IIb or only anti-GP IIIa showed (data not shown). By contrast, induced HEL cells displayed enhancement in both GP IIb and GP IIIa (Fig. 3). GP Ib was not induced de novo in any of the lines, whereas in HEL cells, TPA-induced changes in preexisting GP Ib reactivity were different with different antibodies used (Fig. 3), suggesting possible conformational effects. In addition to differences in certain cell marker reactivity using a single inducer, there were differences between the two inducers, TPA and DMSO, in their ability to enhance the reactivity with a 

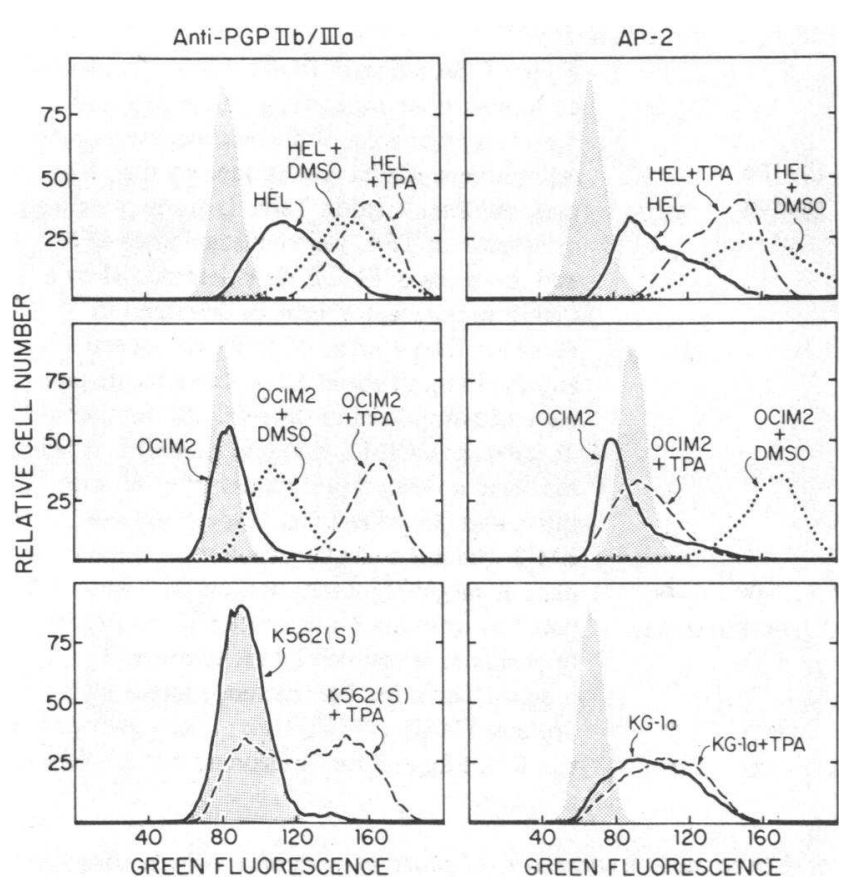

Figure 2. Cells in the absence of inducer (solid line), or with the inducer for $48 \mathrm{~h}$ (dashed or dotted line), were labeled with anti-GP IIb/ IIIa (polyclonal anti-GP IIb/IIIa and monoclonal anti-GP IIb/IIIa: AP-2 [39]) by an indirect immunofluorescence assay, as described in Methods. A significant increase in fluorescence intensity (rightward displacement) is observed after treatment with TPA or DMSO in HEL, OCIM2, and K562(S) and a minor enhancement in KG1a. Shaded area indicates negative controls labeled with an irrelevant antibody.

particular antibody (Fig. 2). From the data presented in Fig. 1, it is apparent that cell lines with no significant expression of platelet glycoproteins (constitutive or induced) showed very low levels of PDGF-like secretion, even after induction. Nevertheless, a quantitative correlation between the abundance of plateletmegakaryocytic marker expression and PDGF secretion was not found.

Characteristics of induced secretion of PDGF-like molecules by three cell lines: OCIM2, K562(S) and HEL. The kinetics of accumulation in culture medium of the PDGF-like molecules by the three highest producers were evaluated over the first 48 $h$ with or without the addition of TPA. As shown in Fig. 4, the rate of PDGF secreted into the medium, expressed as nanograms/ $10^{6}$ cells per $6 \mathrm{~h}$ remained fairly constant in noninduced cells. However, after induction with TPA, this rate was significantly increased and reached maximal levels at approximately $24 \mathrm{~h}$. In a separate experiment with OCIM 2 only, maximal levels were maintained for $6 \mathrm{~d}$ and resulted in continual accumulation of PDGF-like molecules in the medium (Fig. 5). These kinetic data on PDGF accumulation in media after TPA induction suggested that de novo protein synthesis is required. Indeed, when cycloheximide or actinomycin D were continuously present in OCIM2 treated with TPA (Table II), synthesis of PDGF-like molecules was significantly blocked, although cell viability or induction of adherence by TPA was unaffected (data not shown).

A separate experiment was designed to determine whether production of PDGF-like molecules was dependent on cell
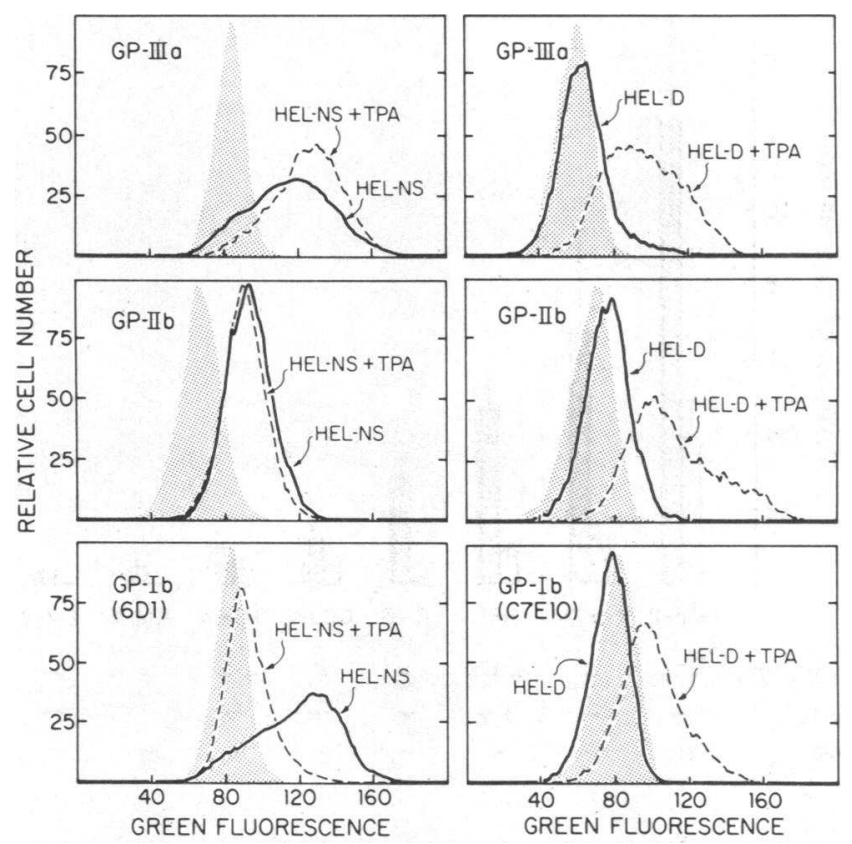

Figure 3. Cytofluorometric profiles of two clones from HEL cells labeled with antibodies against GP IIIa, GP IIb, and GP Ib, before (solid line) and after (dashed line) treatment with TPA. Clone HEL-NS shows high positivity (log plot) with all three antibodies and little or no change after treatment. Clone HEL-D shows low positivity with all three antibodies before treatment, but augmentation after TPA treatment. Enhancement in GP Ib was only observed when Ab C7E1O but not when 6D1 was used in this and in five other separate HEL clones tested after TPA or DMSO addition. (Shaded areas represent profiles of negative control cells). The data in this figure as well as those in Fig. 2 show the independence in the expression and induction of the several platelet glycoproteins expressed in the erythroleukemic lines.

growth and DNA synthesis. As a result of treatment with TPA or DMSO, growth of the erythroleukemic cells is essentially abrogated. To determine whether the growth status of the cells affected production of PDGF-like molecules, the proliferative activity of HEL cells was independently modulated by two different approaches: either it was inhibited by the addition of thymidine ( $2 \mathrm{mM}$ for $48 \mathrm{~h}$ ) or the cells were examined at different stages of growth: stationary phase (at high cell densities) vs. exponential cell growth. As shown in Table III, production of PDGF-like molecules by HEL cells was independent of growth rate. Induction by TPA or DMSO was comparable in a growing state or in a state in which cell growth was markedly restricted. Therefore, absence of proliferation, commonly observed after treatment with TPA, cannot explain release of PDGF-like material.

Demonstration of $c$-sis/PDGF-B- and of PDGF-A-related transcripts in hemopoietic cell lines before and after addition of $T P A$. To determine whether synthesis and secretion of PDGFlike molecules by the erythroleukemic cells is associated with csis expression (B-chain of PDGF as described by Johnson et al. [44]), preparations of poly A(+) RNA from untreated K562(S), OCIM2, HEL, HL-60, and U937 cells were tested in dot blot and in Northern blot hybridization experiments, using as a probe a $1.7-\mathrm{kb}$ cloned fragment representing the $3^{\prime}$ exon of human csis (37). Virtually undetectable levels of c-sis transcripts were found in all the lines tested before induction (Fig. 6 and data not shown). After addition of TPA, however, the highest induc- 


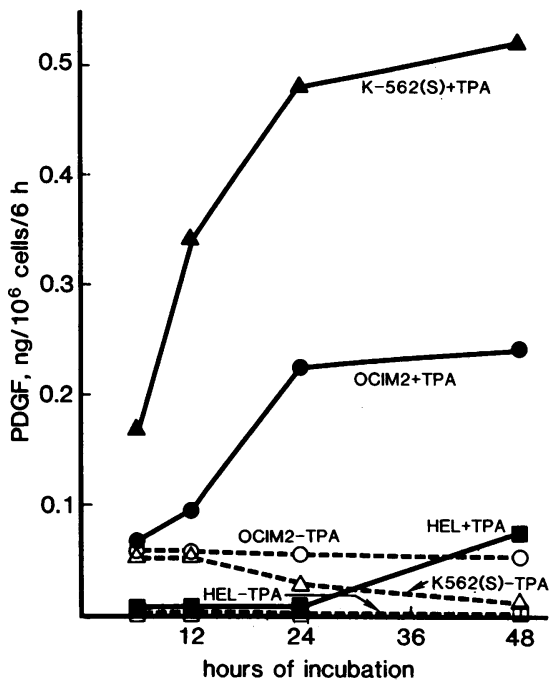

Figure 4. Kinetics of release of PDGF-like molecules by OCIM2, K562(S), and HEL, after induction with TPA. Medium conditioned by OCIM2 (circles), K562(S) (triangles), and HEL (squares) in the presence (solid symbols, solid lines) or absence (open symbols, dashed lines) of TPA was collected from the cells at $6,12,24$, and $48 \mathrm{~h}$. At each time point, the cells were separated by centrifugation, and the medium was removed and replaced with fresh medium. PDGF levels were determined by radioreceptor assay as described in Methods, and the data have been normalized to final cell number at $48 \mathrm{~h}$ and to the amount released over a 6 -h period.

tion of c-sis transcription was seen in K562(S) and OCIM2. The size of the c-sis-related transcripts $(4 \mathrm{~kb})$ in these cells was similar to that previously described for human cells $(37,38)$. Peak levels were found at $12 \mathrm{~h}$ post-TPA addition in K562(S) cells and there was a decrease 24 and $48 \mathrm{~h}$ later. By contrast, for OC1M2 peak levels were not reached until $24 \mathrm{~h}$ and were maintained at about the same level until $48 \mathrm{~h}$. Induction of c-sis transcription in HEL cells was $\sim 10$-fold less than OCIM 2 cells (data not shown), and U-937 line showed a significant induction of c-sis expression (data not shown). PDGF-A mRNA transcripts (40) were not detectable in all lines before induction, but they were strongly induced in K562(S) cells and less so in OCIM2 after TPA addition (Fig. 7 and data not shown).

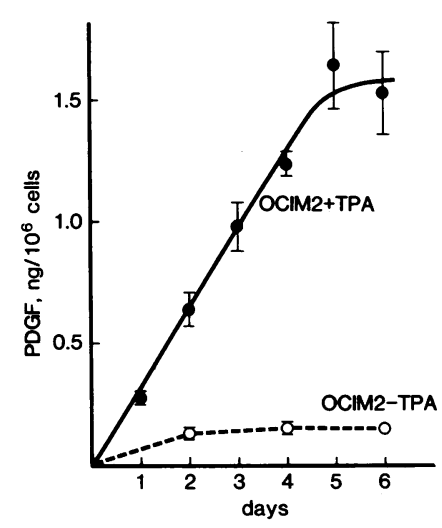

Figure 5. Accumulation of PDGF-like molecules in medium conditioned by OCIM2 over $6 \mathrm{~d}$. Medium conditioned by OCIM 2 cells in the presence (solid circle) or absence (open circle) of TPA was collected at the indicated times from separate cultures of initially 50 $\times 10^{6}$ cells. The final cell number was determined at the time of collection and the level of PDGF-like molecules for each collection was determined for the medium after removal of the cells by centrifugation.

PDGF-levels were determined by radioreceptor assay as described in Methods and have been normalized to final cell number. The mean and standard error of duplicate assays (each at three doses) is plotted.
Table III. Production of PDGF-like Molecules by HEL Is Not Dependent on Cell Proliferation

\begin{tabular}{llll}
\hline & & \multicolumn{2}{l}{ PDGF } \\
\cline { 3 - 4 } Cells & $\begin{array}{l}\text { Treatment for } \\
\text { cell arrest }\end{array}$ & Growing & Stationary \\
\hline & & $n g / 10^{6}$ cells & $n g / 10^{6}$ cells \\
HEL & Cell density & 0.095 & 0.075 \\
HEL + DMSO & Cell density & 0.245 & 0.213 \\
HEL & Thymidine & 0.07 & 0.07 \\
HEL + TPA & Thymidine & 0.55 & 0.75 \\
& & & \\
\hline
\end{tabular}

\section{Discussion}

In general, human lymphoid, myeloid, or monocytic cell lines express in the majority of their cells a phenotype largely compatible with their lineage affiliation. By contrast, all the human erythroleukemic lines that we have studied express features of more than one lineage. Thus, in addition to erythroid surface markers and hemoglobin formation, they express markers of megakaryocytic and/or myelomonocytic lineage $(20-23,27)$. Although the significance of the coexpression of megakaryocytic and erythroid markers within the same cell population is at present unclear (45), it has been possible to modulate these two phenotypes in vitro, independently or in combination. For example, treatment of HEL or K562 cells with TPA abrogates the expression and inducibility of erythroid markers $(46,47)$, whereas it enhances the expression of megakaryocytic markers (23). In this regard our present data on amplification of megakaryocytic markers, including the previously unstudied lines OCIM2, $\mathrm{K} 562$ (S), and KG-1a, expand initial observations made in HEL and $\mathrm{K} 562$ cells.

Evaluation of megakaryocytic/platelet antigen expression by different antibodies than the ones used previously (23) uncovered independence in the expression and regulation of the various platelet glycoproteins. For example, GP Ib was detected in HEL cells only, and K562(S) cells expressed virtually only GP IIIa, either before or after induction; by contrast, both GP IIb and GP IIIa were induced in HEL and OCIM2 cells.

In addition to enhancement of surface megakaryocytic markers in response to TPA, a major feature of TPA induction examined in detail here was the augmentation in secretion of a

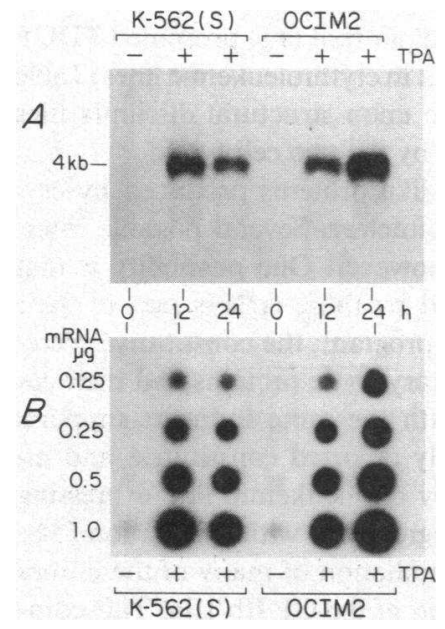

Figure 6. Enhanced expression of PDGF-B-related mRNA in OCIM2 and K562(S) cells after addition of TPA. $(A)$ Northern blot of $5 \mu \mathrm{g}$ of poly A+ mRNA per lane at 0,12 , and $24 \mathrm{~h}$ after TPA addition. $(B)$ Increasing quantities, as indicated, of poly A+ mRNA from the $0-, 12-$ and 24-h samples were spotted onto nitrocellulose filters. All samples were hybridized to a 1.7-kb Bam c-sis fragment, representing the $3^{\prime}$ exon of human c-sis as described in Methods. Exposure time was $20 \mathrm{~h}$. 


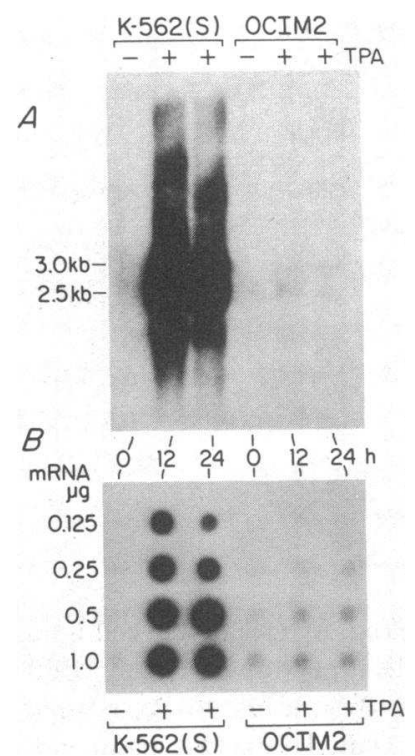

Figure 7. Induction of PDGF-A mRNA after TPA treatment of K562(S) and OCIM2. Blots shown in Fig. 6 were rehybridized, after decay, with the 1.3-kb cDNA clone (D1) representing the PDGF-A chain. $(A)$ Northern blot; $(B)$ Dot blot, with quantities of poly $\mathrm{A}+$ RNA, as shown in Fig. $6 B$

PDGF-like protein by the erythroleukemic cell lines OCIM2, K562(S), HEL, and OCIM1. Apart from the erythroleukemic lines, the only other cell line with expression of megakaryocytic markers and secretion of significant amounts of PDGF-like protein was the KG-1a line. This was a previously undisclosed feature for KG-1a cells. Release of PDGF-like molecules in response to TPA appears to be largely independent of morphologic changes (i.e., induction of an adherent, macrophage-like morphology) or cessation of cell proliferation that follows TPA treatment. A concurrent induction in the expression of previously undetectable sis-related/PDGF-B mRNA, however, was noted. Highest levels were seen in OCIM2 and K562. The latter also showed a distinct and impressive induction of non-sis/PDGFA mRNA. The nature of the preexisting and induced PDGFlike protein(s) and their relationship to the induction of PDGF$A$ and PDGF-B mRNA are currently under study.

Among previously described cell types secreting PDGF-like molecules, endothelial cells seem to share some common features with the erythroleukemic lines. Thus, these two cell types, which are not target cells for PDGF (48; E. Raines, unpublished observation), display constitutive and TPA induced secretion of PDGF $(11,49,50)$, and they both synthesize several of the platelet-megakaryocyte proteins (i.e., GP IIb/IIIa, factor VIII, vWF, or platelet factor 4) $(51,52)$. A notable difference, however, is that thrombin (53) and inactive phorbol (11) promoted PDGF release in endothelial cells but not in erythroleukemic lines (Table II). Such differences may hinge upon structural dissimilarities among PDGF forms produced by the two cell types.

The significance of PDGF-like proteins produced by erythroleukemic cells is presently unclear. Several possible interpretations can be forwarded, however. One possibility is that the PDGF-like activity secreted by these cells is part of their megakaryocytic differentiation program; the constitutive secretion of PDGF and other megakaryocytic proteins and their coordinate enhancement seen with the same inducers supports this postulate. Also, the recently reported constitutive and inducible PDGF-like secretion by one leukemic line expressing megakaryocytic markers is in agreement with this notion (54). However, the megakaryocytic affiliation of many of these lines is largely based on the expression of the GP IIb/IIIa. This com- plex, originally thought to be unique to the platelet/megakaryocyte, belongs to a family of cytoadhesive proteins present in several cell types (55-58), including early hemopoietic progenitor cells (59), thus raising the possibility that its presence may reflect the cells' immature, progenitor-like phenotype rather than a pathway committed phenotype. Another possibility, recently suggested for HL-60 and U-937 cells $(60,61)$ is that PDGF-like secretion is associated with the expression or the potential to express a monocytic-like phenotype. Indeed, both HEL and OCIM2 assume a typical macrophage-like phenotype after TPA (47), whereas K562 cells only partially do so. However, the monocytic HL-60 and U-937, in contrast to erythroleukemic cells, do not display, in the absence of TPA, constitutive secretion of PDGF and expression of megakaryocytic proteins. Finally, given the neoplastic nature of the cells, PDGF secretion may be consequential to their transformation process and possibly vital to the growth and proliferation of the cells through an as yet undefined paracrine mechanism.

To decide between these possibilities and to understand the significance of secreted PDGF, further studies on the structural and functional features of PDGF-like activity elaborated by these hemopoietic cell lines, as compared with PDGF analogs secreted by other cells, are required. Nevertheless, our data on the expression of both A- and B-chain genes (and secretion of PDGFlike molecules) provide model systems for studying events associated with PDGF analog secretion by hemopoietic cells.

\section{Acknowledgments}

We thank Darcey Clark for her expert technical assistance in many phases of this work and Drs. J. Roth, D. Nugent, R. Hoffman and Jan A. van Mourik for their donations of antibody samples. We are also grateful to Dr. Carl-Henrik Heldin for the PDGF-A cDNA probe and to Susie Quick for her secretarial assistance.

This work was supported by grants AM-30852 and HL-18645 from the National Institutes of Health and by a grant from R. Nabisco, Inc.

\section{References}

1. Ross, R., and A. Vogel. 1978. The platelet-derived growth factor. Cell. 14:203-210.

2. Scher, C. D., R. C. Shepard, H. N. Antoniades, and C. D. Stiles 1979. Platelet-derived growth factor and the regulation of the mammalian fibroblast cell cycle. Biochim. Biophys. Acta. 560:217-241.

3. Westmark, B., C.-H. Heldin, B. Ek, A. Johnsson, K. Mellstrom, M. Nister, and A. Wasteson. 1983. Biochemistry and biology of plateletderived growth factor. In Growth and Maturation Factors. Vol. 1. G. Guroff, editor. John Wiley \& Sons, New York. 73-115.

4. Ross, R., E. W. Raines, and D. F. Bowen-Pope. 1986. The biology of platelet-derived growth factor. Cell. 46:155-169.

5. Bowen-Pope, D. F., R. A. Seifert, and R. Ross. 1985. The plateletderived growth factor receptor. In Control of Animal Cell Proliferation. Vol. 1. A. L. Boynton and H. L. Leffert, editors. Academic Press, Inc., New York. 281-312.

6. Stiles, C. D. 1983. The molecular biology of platelet-derived growth factor. Cell. 33:653-655.

7. Ross, R. 1986. The pathogenesis of atherosclerosis: an update. $N$. Engl. J. Med. 314:488-500.

8. Chernoff, A., R. F. Levine, and D. S. Goodman. 1980. Origin of platelet-derived growth factor in megakaryocytes in guinea pigs. J. Clin. Invest. 65:926-930.

9. Castro-Malaspina, H., E. M. Rabellino, A. Yen, R. L. Nachman, and M. A. S. Moore. 1981. Human megakaryocyte stimulation of proliferation of bone marrow fibroblasts. Blood. 57:781-787. 
10. DiCorleto, P. E., and D. F. Bowen-Pope. 1983. Cultured endothelial cells produce a platelet-derived growth factor-like protein. Proc. Natl. Acad. Sci. USA. 80:1919-1923.

11. Fox, P. L., and P. E. DiCorleto. 1984. Regulation of production of a platelet-derived growth factor-like protein by cultured bovine aortic endothelial cells. J. Cell. Physiol. 121:298-308.

12. Shimokado, K., E. W. Raines, D. K. Madtes, T. B. Barrett, E. P. Benditt, and R. Ross. 1985. A significant part of macrophage-derived growth factor consists of at least two forms of PDGF. Cell. 43:277-286.

13. Mornex, J. F., Y. Martinet, K. Yamauchi, P. B. Bitterman, G. R. Grotendorst, A. Chytil-Weir, G. R. Martin, and R. G. Crystal. 1986. Spontaneous expression of the c-sis gene and release of a platelet-derived growth factorlike molecule by human alveolar macrophages. J. Clin. Invest. 78:61-66.

14. Martinet, Y., P. B. Bitterman, J.-F. Mornex, G. R. Grotendorst, G. R. Martin, and R. G. Crystal. 1986. Activated human monocytes express the c-sis proto-oncogene and release a mediator showing PDGFlike activity. Nature (Lond.). 319:158-160.

15. Seifert, R. S., S. M. Schwartz, and D. F. Bowen-Pope. 1984. Developmentally regulated production of platelet-derived growth factorlike molecules. Nature (Lond.). 311:669-671.

16. Goustin, A. S., C. Betsholtz, S. Pfeifer-Ohlsson, H. Persson, J. Rydnert, M. Bywater, G. Holmgren, C.-H. Heldin, B. Westermark, and R. Ohlsson. 1985. Coexpression of the sis and myc proto-oncogenes in developing human placenta suggests autocrine control of trophoblast growth. Cell. 41:301-312.

17. Bowen-Pope, D. F., A. Vogel, and R. Ross. 1984. Production of platelet-derived growth factor-like molecules and reduced expression of platelet-derived growth factor receptors accompany transformation by a wide spectrum of agents. Proc. Natl. Acad. Sci. USA. 81:2396-2400.

18. Bleiberg, I., A. K. Harvey, G. Smale, and G. R. Grotendorst. 1985. Identification of a PDGF-like mitoattractant produced by NIH/ 3 T3 cells after transformation with SV-40. J. Cell. Physiol. 123:161166.

19. Stroobant, P., W. J. Gullick, M. D. Waterfield, and E. Rozengurt. 1985. Highly purified fibroblast-derived growth factor, an SV-40 transformed fibroblast-secreted mitogen, is closely related to platelet-derived growth factor. EMBO (Eur. Mol. Biol. Organ.) J. 4:1945-1949.

20. Gerwitz, A., E. J. Genz, Jr., T. A. Rado, and R. Hoffman. 1982. Expression of platelet glycoproteins by the human leukemia cell line K562. Clin. Res. 30:502A. (Abstr.)

21. Tabilio, A., P. Pelicci, G. Vinci, P. Mannoni, C. I. Civin, W. Vainchenker, U. Testa, M. Lipinski, H. Rochant, and J. Breton-Gorius. 1983. Myeloid and megakaryocytic properties of K562 cell lines. Cancer Res. 43:4569-4574.

22. Papayannopoulou, T., T. Yokochi, B. Nakamoto, and P. Martin. 1983. The surface antigen profile of HEL cells. In Globin Gene Expression and Hematopoietic Differentiation. G. Stamatoyannopoulos and A. W. Nienhuis, editors. Alan R. Liss, Inc., New York. 277-292.

23. Tabilio, A., J. P. Rosa, U. Testa, N. Kieffer, A. T. Nurden, M. C. DelCanizo, J. Greton-Gorius, and W. Vainchenker. 1984. Expression of platelet membrane glycoproteins and a-granule proteins by a human erythroleukemia cell line (HEL). EMBO (Eur. Mol. Biol. Organ.) J. 3: 453-459.

24. Andersson, L. C., K. Nilsson, and C. G. Gahmberg. 1979. K562: a human erythroleukemic cell line. Int. J. Cancer. 23:143-147.

25. Cioe, L., A. McNab, H. R. Hubbell, P. Meo, P. Curtis, and G. Rovera. 1981. Differential expression of the globin genes in human leukemia $\mathrm{K} 562$ (S) cells induced to differentiate by hemin or butyric acid. Cancer. Res. 42:237-243.

26. Martin, T., and T. Papayannopoulou. 1982. HEL cells: a new human erythroleukemia cell line with spontaneous and induced globin expression. Science (Wash. DC). 216:1233-1234.

27. Papayannopoulou, T., M. Tweeddale, H. Messner, and B. Nakamoto. 1984. Globin phenotype and surface markers of two new human erythroleukemia lines. Blood. 64(Suppl. 1):116a.

28. Koeffler, H. P., and D. W. Golde. 1978. Acute myelogenous leukemia: a human cell line responsive to colony stimulating activity. Science (Wash. DC). 200:1153-1154.

29. Koeffler, H. P., R. Billing, A. J. Lusis, R. Sparkes, and D. W. Golde. 1980. An undifferentiated variant derived from the human acute myelogenous leukemia cell line (KG-1). Blood. 56:265-273.

30. Collins, S. J., R. C. Gallo, and R. E. Gallagher. 1977. Continuous growth and differentiation of human myeloid leukaemic cells in suspension culture. Nature (Lond.). 270:347-349.

31. Keating, A., P. J. Martin, I. D. Bernstein, T. Papayannopoulou, W. Raskind, and J. W. Singer. 1983. EM-2 and EM-3: two new $\mathbf{P h}^{1}$ + myeloid cell lines. In Normal and Neoplastic Hematopoiesis. D. W. Golde and P. A. Marks, editors. Alan R. Liss, Inc., New York. 513-520.

32. Sundstrom, C., and K. Nilsson. 1976. Establishment and characterization of a human histiocytic lymphoma cell lines (U-937). Int. J. Cancer. 17:565-577.

33. Bowen-Pope, D. F., and R. Ross. 1985. Methods for studying the platelet-derived growth factor receptor. Methods Enzymol. 109:69100.

34. Raines, E. W., and R. Ross. 1985. Purification of human plateletderived growth factor. Methods Enzymol. 109:749-773.

35. Chirgwin, J., A. Przybyla, R. MacDonald, and W. Rutter. 1979. Isolation of biologically active ribonucleic acid from sources enriched in ribonuclease. Biochemistry. 18:5294-6001.

36. Aviv, H., and P. Leder. 1972. Purification of biologically active globin messenger RNA by chromatography on oligothymidylic acid-cellulose. Proc. Natl. Acad. Sci. USA. 69:1408-1411.

37. Maniatis, T., E. Fritsch, and J. Sambrook. 1982. Molecular Cloning: A Laboratory Manual. Cold Spring Harbor Laboratory Press, Cold Spring Harbor, NY. 198-200.

38. Dalla-Favera, R., E. Gelmann, R. Gallo, and F. Wong-Staal. 1981. A human onc gene hemologous to the transforming gene ( $\mathrm{v}$-sis) of simian sarcoma virus. Nature (Lond.). 292:31-35.

39. Eva, A., K. Robbins, P. Andersen, A. Srinivasan, S. Tronick, E. P. Reddy, N. W. Ellmore, A. T. Galen, J. A. Lautenberger, T. S. Papas, E. H. Westin, F. Wong-Staal, R. C. Gallo, and S. A. Aaronson. 1982. Cellular genes analogous to retroviral onc genes are transcribed in human tumour cells. Nature (Lond.). 295:116-119.

40. Betsholtz, C., A. Johnsson, C.-H. Heldin, B. Westermark, P. Lind, M. S. Urdea, R. Eddy, T. B. Shows, K. Philpott, A. L. Mellor, T. J. Knott, and J. Scott. 1986. cDNA sequence and chromosomal localization of human platelet-derived growth factor A-chain and its expression in tumour cell lines. Nature (Lond.). 320:695-699.

41. Montgomery, R. R., T. J. Kunicki, C. Taves, D. Pidard, and M. Corcoran. 1983. The diagnosis of Bernard-Soulier syndrome and Glanzmann's thrombasthenia with a monoclonal assay on whole blood. $J$. Clin. Invest. 71:385-389.

42. Thiagarajan, P., B. Perussia, L. DeMarco, K. Wells, and G. Trinchieri. 1983. Membrane proteins on human megakaryocytes and platelets identified by monoclonal antibodies. Am. J. Hematol. 14:255-269.

43. Coller, B. S., E. I. Peerschke, L. E. Scudder, and C. A. Sullivan. 1983. Studies with a murine monoclonal antibody that abolishes ristocetin-induced binding of von Willebrand factor to platelets. Blood. 61: 99-110.

44. Johnsson, A., C.-H. Heldin, O. Wasteson, B. Westermark, T. F. Deuel, J. S. Huang, P. H. Seeburg, A. Gray, A. Ullrich, G. Scrace, P. Stroobant, and M. D. Waterfield. 1984. The c-sis gene encodes a precursor of the B chain of platelet-derived growth factor. EMBO (Eur. Mol. Biol. Organ.) J. 3:921-928.

45. Graves, M. F., L. C. Chan, A. J. W. Furley, S. M. Watt, and H. V. Molgaard. 1986. Lineage promiscuity in hemopoietic differentiation and leukemia. Blood. 67:1-11.

46. Fukuda, M. 1981. Tumor-promoting phorbol diester-induced specific changes in cell surface glycoprotein profile of K562 human leukemic cells. Cancer Res. 41:4621-4628.

47. Papayannopoulou, T., B. Nakamoto, T. Yokochi, A. Chait, and R. Kannagi. 1983. Human erythroleukemia cell line (HEL) undergoes a drastic macrophage-like shift with TPA. Blood. 62:832-845.

48. Kazlauskas, A., and P. E. DiCorleto. 1985. Cultured endothelial 
cells do not respond to a platelet-derived growth factor-like protein in an autocrine manner. Biochim. Biophys. Acta. 846:405-412.

49. Barrett, T. B., C. M. Gajdusek, S. M. Schwartz, J. K. McDougall, and E. P. Benditt. 1984. Expression of the sis gene by endothelial cells in culture and in vivo. Proc. Natl. Acad. Sci. USA. 81:6772-6774.

50. Collins, T., D. Ginsburg, J. M. Boss, J. H. Orkin, and J. S. Pober. 1985. Cultured human endothelial cells express platelet-derived growth factor chain 2:cDNA cloning and structural analysis. Nature (Lond.). 316:748-750.

51. Fitzgerald, L. A., I. F. Charo, and D. R. Phillips. 1985. Human and bovine endothelial cells synthesize membrane proteins similar to human platelet glycoproteins IIb and IIIa. J. Biol. Chem. 260:1089310896.

52. Van Mourik, J. A., O. C. Leeksma, J. H. Reinders, P. G. de Groot, and J. Zandbergen-Spaargaren. 1985. Vascular endothelial cells synthesize a plasma membrane protein indistinguishable from the platelet membrane glycoprotein. J. Biol. Chem. 260:11300-11306.

53. Harlan, J. M., P. J. Thompson, R. R. Ross, and D. F. BowenPope. 1986. $\alpha$-Thrombin induces release of platelet-derived growth factorlike molecule(s) by cultured human endothelial cells. J. Cell Biol. 103 1129-1133.

54. Pantazis, P., D. A. Morgan, I. Brodsky, and H. N. Antoniades. 1985. Platelet-derived growth factor polypeptides in human megakaryoblastic-like cell lines. In Cancer Cells 3: Growth Factors and Transformation. Cold Spring Harbor Laboratory Press, Cold Spring Harbor, NY. 153-157.

55. Charo, I. F., L. A. Fitzgerald, and D. R. Phillips. 1985. Human smooth muscle cells and a fibroblast-like cell line (MG-63) express surface glycoproteins (GP) that are similar to platelet GP IIb \& GP IIIa. Blood. 66(Suppl. 1):302a. (Abstr.)

56. Burns, G. F., L. Cosgrove, T. Triglia, J. A. Beall, A. F. Lopez, J. A. Werkmeister, C. G. Begley, A. P. Haddad, A. J. F. d'Apice, M. A. Vadas, and J. C. Cawley. 1986. The IIb-IIla glycoprotein complex that mediates platelet aggregation is directly implicated in leukocyte adhesion. Cell. 45:269-280.

57. Cosgrove, L. J., M. S. Sandrin, P. Rajasekariah, and I. F. C. McKenzie. 1986. A genomic clone encoding the $\alpha$ chain of the OKM1, LFA-1, and platelet glycoprotein IIb-IIIa molecules. Proc. Natl. Acad. Sci. USA. 83:752-756.

58. Plow, E. F., J. C. Loftus, E. G. Levin, D. S. Fair, D. Dixon, J. Forsyth, and M. H. Ginsberg. 1986. Immunologic relationship between platelet membrane glycoprotein GPIIb/IIIa and cell surface molecules expressed by a variety of cells. Proc. Natl. Acad. Sci. USA. 83:60026006.

59. Fraser, J. K., M. F. Leahy, and M. V. Berridge. 1986. Expression of antigens of the platelet glycoprotein IIb/IIIa complex on human hematopoietic stem cells. Blood. 68:762-769.

60. Pantazis, P., L. Lanfrancone, P. G. Pelicci, R. Dalla-Favera, and H. N. Antoniades. 1986. Human leukemia cells synthesize and secrete proteins related to platelet-derived growth factor. Proc. Natl. Acad. Sci. USA. 83:5526-5530.

61. Pantazis, P., E. Sariban, D. Kufe, and H. N. Antoniades. 1986. Induction of c-sis gene expression and synthesis of platelet-derived growth factor in human myeloid leukemia cells during monocytic differentiation. Proc. Natl. Acad. Sci. USA. 83:6455-6459. 